\title{
STUDENTS 'OPINION OF A SELECTED EDUCATIONAL INSTITUTION ON THE USE OF TECHNOLOGICAL INNOVATION IN ORDINARY LIFE \\ Peter Jucha $^{1}$, Tatiana Corejova ${ }^{2}$
}

\begin{abstract}
Technological progress is becoming more significant every year, and people are witnessing a number of innovations that are becoming part of their daily lives. The development of technology is advancing at great speed because the needs and requirements of people are becoming more and more difficult to meet, and so innovations are being developed to help fulfill these needs. However, not all people accept technological progress and innovation positively. The aim of the paper is to evaluate the opinion of people, specifically students of the selected higher education institution, on new technologies and innovations. In particular we wish to evaluate their general attitude towards technological innovation, but also their views on the use of specific technologies such as robots, drones or autonomous vehicles. Students' responses as to whether they would like them and whether they would be satisfied with the aforementioned innovations being widely used in the future vary. Some would benefit from the use of such innovations, others would not. Some students don't like it because people could lose their jobs and others don't really believe in such innovations. The results of the paper provide an evaluation of all the answers given by the students.
\end{abstract}

UDC Classification: 011, DOI: https://doi.org/10.12955/pns.v2.150

Keywords: autonomous vehicles, drones, innovations, technology, robots

\section{Introduction}

Technology and technological innovations each year increasingly affects the world around us. They influence both various activities people perform as well as the people specifically performing those activities. Technological innovations have caused changes to communications between people, changes in human relationships, changes in how to access information and their acquisition as well as have caused changes in transport (Madlenak \& Madlenakova, 2014).

Nowadays technology is increasingly more frequent changes. Many technologies that were considered new a few years ago and which were frequently used and represented technological advances are already today replaced by new technologies. This happens because of technological progress and the development of innovations which introduce substitution technologies to existing technologies, but also, entirely new technological solutions (Pathan, 2018). But not everything is just about technological change. The fact is that there are many different technologies at any time that can also co-exist (Rosenberg, 1976).

Innovations are implemented through changes in various areas of corporate activities, departments, thinking and attitudes of employees. According to the Oslo Manual for measuring innovation, four types of innovations are presented: product innovation, process innovation, marketing innovation and organizational innovation. Product innovation represents a good or service that is new or significantly improved. Process innovation represents a new or significantly improved production or delivery method. Marketing innovation represents a new marketing method involving significant changes. Organizational innovation represents a new organizational method in business practice, workplace organization or external relations (OECD). Product innovations and process innovations are among technological innovations while marketing innovations and organizational innovations are among non-technological innovations (Statistical office of the Slovak republic). Each innovative activity in certain organizations is manifested in the proposals of new products or product rows that have been unknown to the consumer and subsequently they should begin to satisfy his needs (Jamnický, 2013). For example, in the service sector, customer satisfaction became the central interest of enterprises providing services. They are trying to improve the quality of their services to maintain customer loyalty (Strenitzerova \& Gana, 2018). At present, it is also important to customers how a particular product has been made or service realized and not just the final form of the product or service (Jankal \& Janaklova, 2016). Technological innovation can be characterized as a process of creative destruction where new technologies push old and lower-class technologies out of the market which allows for subsequent performance improvements in the areas that use those specific technologies. The new technology can then either increase the competence, continue to build and improve know-how to strengthen the organization's market position

\footnotetext{
${ }^{1}$ University of Zilina, Faculty of Operation and Economics of Transport and Communications, Department of Communications, peter.jucha@fpedas.uniza.sk

${ }^{2}$ University of Zilina, Faculty of Operation and Economics of Transport and Communications, Department of Communications, tatiana.corejova@uniza.sk
} 
or render existing know-how obsolete and enabling new entrants to become technologically able competitors in a particular market (Baum, 2001). Technological innovation can also be considered as an economic function through which new technologies are introduced into production and consumption. This means that it recognizes new technological opportunities and organizes human and financial resources that are needed to transform these options into products and processes while recognizing the maintenance of the necessary activities. This is an important function because technological progress plays a key role in improving people's living standards (Scherer, 2001).

Technological innovations are also represented in the field of the so called "last mile" which is the last section of the distribution of goods or packages between a particular company and the final consumer of the goods or service, with the recipient receiving the goods at home or at an agreed place (Gnap \& Benova, 2018). The last mile is the final part of the supply chain and is often described to as the most important element of the process in delivering orders (Janevic \& Wikenbach, 2020).

In the field of last mile delivery, technologies manage the level of innovation in the offer of products and services and at the same time transform the way in which communication between the delivery provider and their customers is ensured. Customers' supply demands are still increasing and new technologies such as robots / artificial intelligence, Internet of Things, Industry 4.0, drones and autonomous vehicles are being explored to satisfy them (Lee et al., 2016).

However, if functioning companies want to implement such technological innovations into their production processes, distribution services and other activities, they should also have to know customer views (Wang et al., 2020).

Consumers and their behavior are determined by technological and non-technological innovations. Due to everyday life, these innovations are more or less accepted by consumers, which is usually related to their habits, age and access to new solutions. A number of innovations are associated with the application of ICT, robots, drones, and autonomous vehicles in everyday life.

This contribution is focused on the issues of consumer access in the age group of university students to the use of technological innovations. Consumer behavior on the one hand and the offer of new solutions on the other raise several questions. How do consumers perceive the introduction of new solutions? Do approaches differ in terms of gender? In the following section, we present the results of the primary research carried out during the COVID-19 pandemic in December 2020.

\section{Methodology}

The main aim of this paper is to analyze what is the approach of consumers to technological innovations and especially what is their opinion on the implementation of robots / artificial intelligence, drones and autonomous vehicles in real life. In order to meet the objective of the paper, primary research was carried out among university students at the Faculty of Operation and Economics of Transport and Communications (PEDAS) at the University of Žilina, in the form of an electronic questionnaire. During the elaboration of the theoretical part of the paper, scientific articles from the Web of Science database were used, as well as other scientific articles, publications, a dictionary, but also Internet resources dealing with the given topic. The methods of analysis and synthesis were mainly used.

The primary research, which was carried out at the PEDAS Faculty at the University of Žilina was based on a basic sample of 2043 university students. With an estimate reliability of $90 \%$, an error rate of $8 \%$, a table value $\mathrm{t}^{2}=2.6896$ and a constant $\sigma^{2}=0.25$, the target sample of students to be addressed was 100 students.

$$
n \geq \frac{N * t^{2}{ }_{1-\frac{\alpha}{2}} * \sigma^{2}}{(N-1) * \Delta^{2}+t^{2}{ }_{1-\frac{\alpha}{2}} * \sigma^{2}}
$$

where:

$\mathrm{N}-$ is base file size,

$t^{2} \_(1-\alpha / 2)$ - is a critical value determined from the tables (critical values of normalized normal distribution),

$\sigma 2$ - is the range calculated from a standard deviation,

$\Delta-$ is the maximum allowable error rate. 
The answers from the questionnaire were divided according to the gender of the respondents and were evaluated verbally and graphically.

The questionnaire consisted of one identification question, one question using the Lickert scale (5 degrees - clearly negative, rather negative, neutral, rather positive, clearly positive) and three openended questions. For open-ended questions, the answer options for the graphs shown in the results were created according to all the types of answers given by respondents.

The following research goals and research assumptions listed in Table 1 were presented for research purposes.

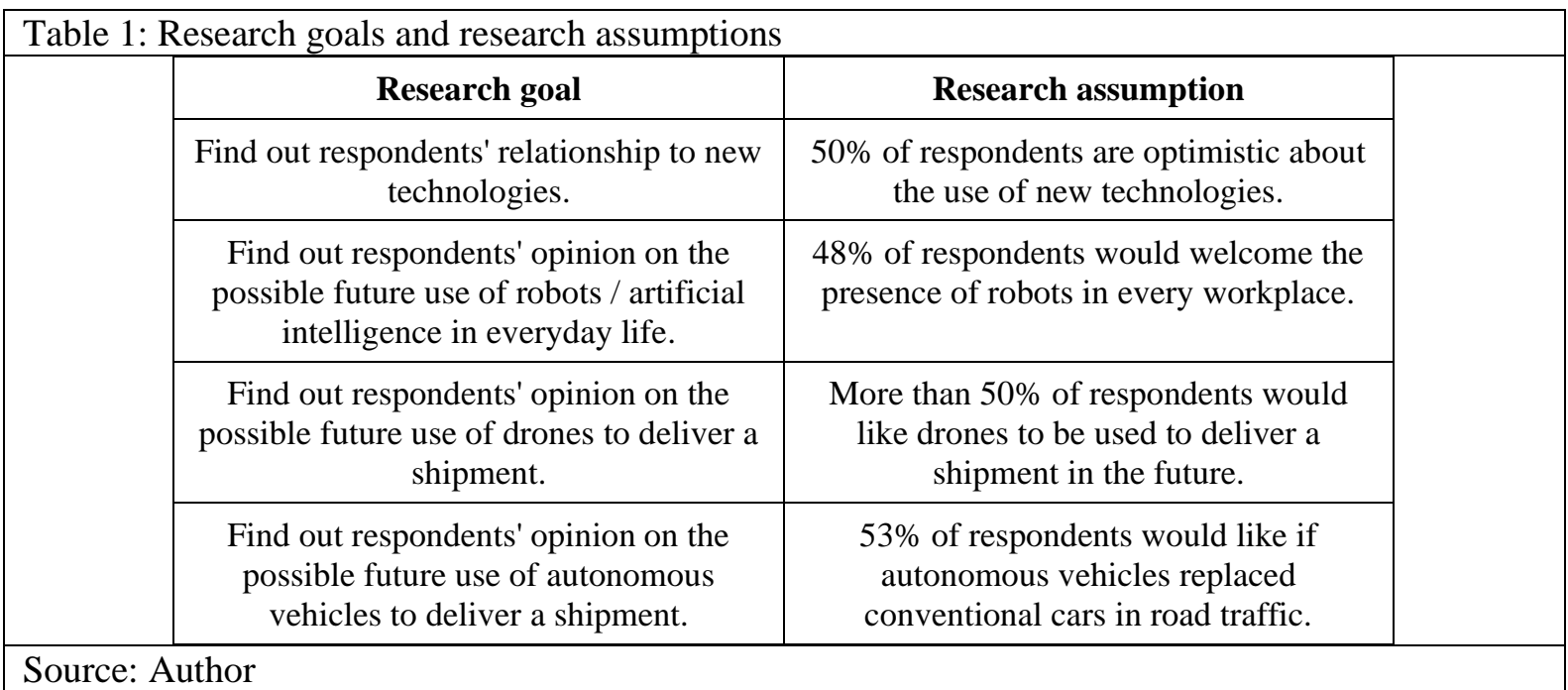

The research assumptions were determined on the basis of the answers of respondents from other surveys that have been conducted in the past in the world. The first was a 2019 survey conducted by $3 \mathrm{M}$, in which 14,025 people from 14 countries expressed their views. The second was a survey from the United Kingdom, in which 2,000 British people responded to topics related to new technologies.

\section{Results}

A total of 105 full-time students of the PEDAS Faculty at the University of Žilina completed the electronic questionnaire, which the respondents filled in in order to obtain answers concerning their relationship to technological innovations and specifically to robots / artificial intelligence, drones and autonomous vehicles.

The questionnaire also contained an identification question concerning the gender of the respondents.

\begin{tabular}{|l|l|}
\hline Figure 1: The gender of the respondents \\
\hline
\end{tabular}

In Figure 1, of the 105 students who completed the questionnaire, 30.5\% (32) were men and $69.5 \%$ (73) were women.

Students' relationship to technological innovation

Another question concerned their general relationship to new technologies or technological innovations. Respondents had a choice of five options. 


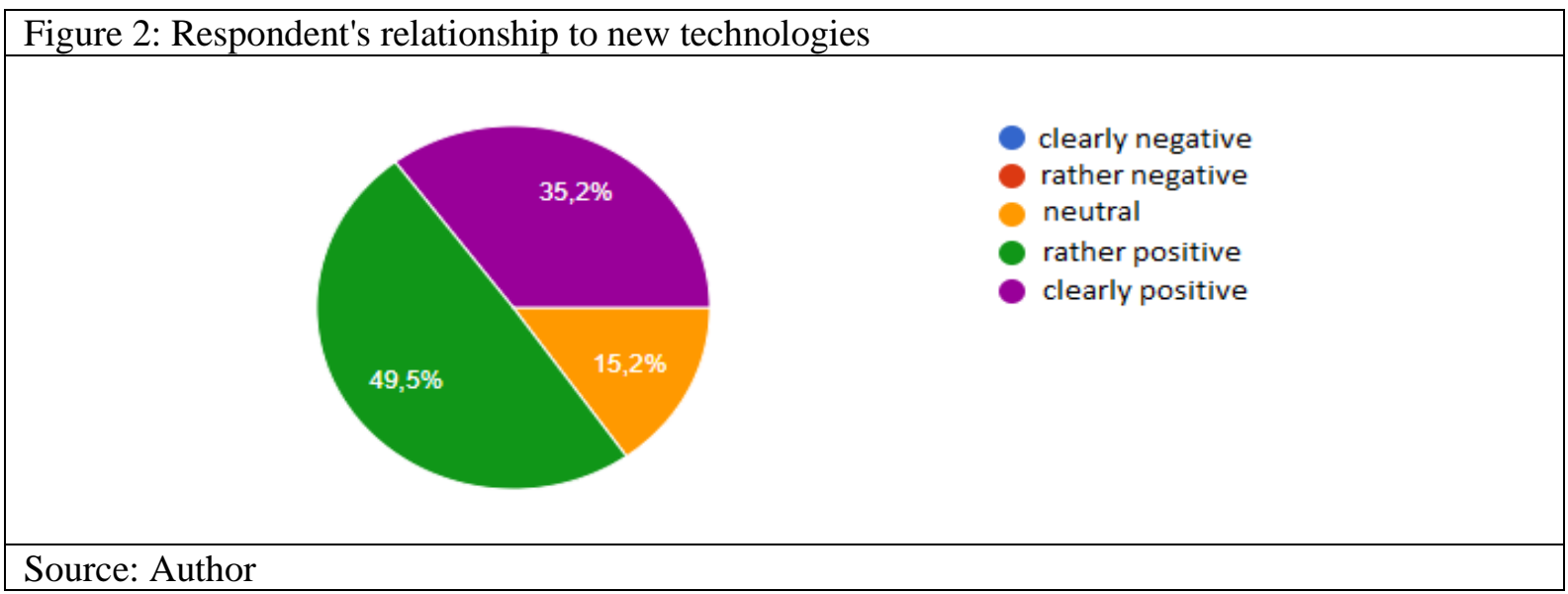

As many as $49.5 \%$ (52) of students, of whom 11 were men and 37 were women, said that their relationship to technological innovation was rather positive.

$35.2 \%$ (37) of students, of whom 18 were men and 19 were women, stated that their relationship to technological innovation is clearly positive.

$15.2 \%$ (16) of students, of whom 3 were men and 13 were women, stated that their relationship to technological innovation was neutral.

None of the students stated that their relationship to technological innovation was negative.

The assumption, in which it was stated that $50 \%$ of respondents are optimistic about the use of new technologies, was confirmed.

\section{Robots / artificial intelligence}

The question about robots / artificial intelligence was as follows:

Would you like to have robots present at every workplace in the future (they might replace some human activities)?

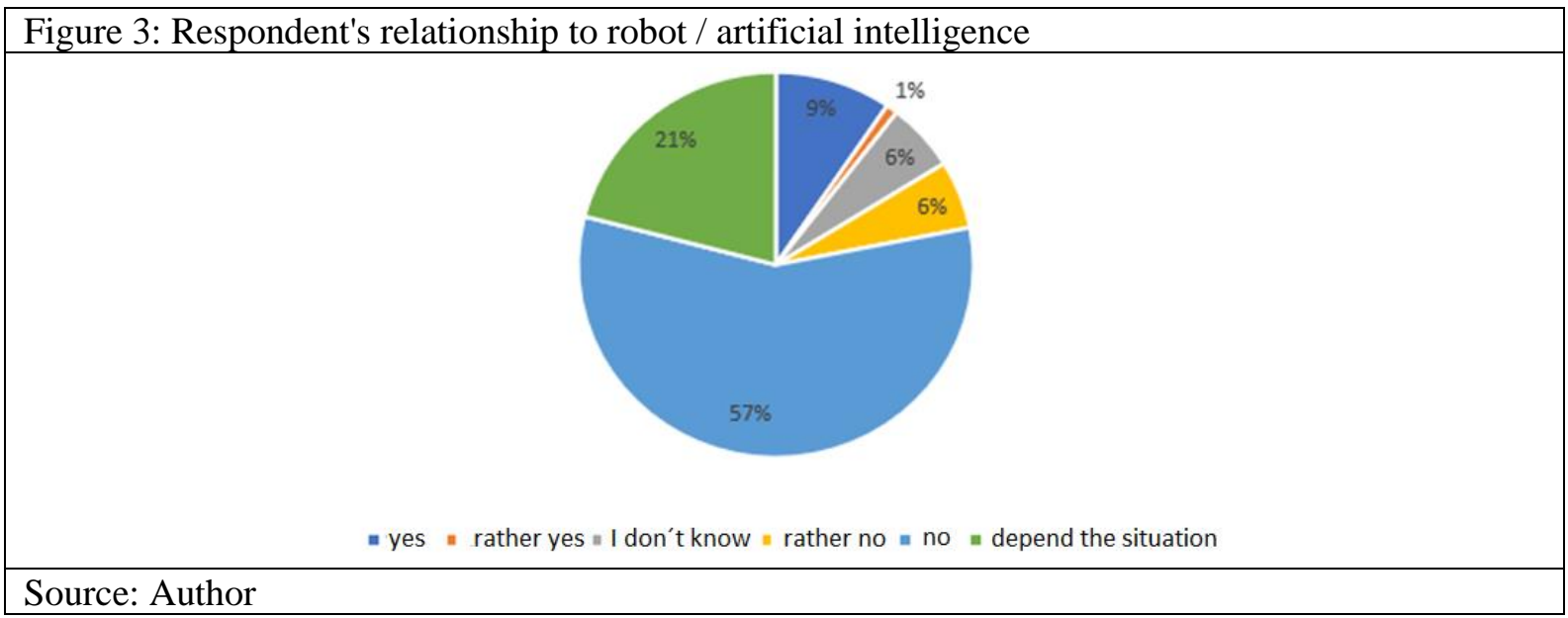

The answer that respondents would like it was given by $9 \%$ (10) of students, of whom 5 were men and 5 were women.

The answer that respondents would not like this was given by $57 \%$ (60) of students, of whom 13 were men and 47 were women. The most common reason why they do not agree is that people would lose their jobs and unemployment would rise.

Less than 6\% (6) of respondents, 3 men and 3 women, said they would rather not like it and less than $1 \%$ (1) of respondents, woman, said she would rather like it.

Less than 6\% (6) of respondents, of which 1 was a man and 5 were women, did not know how to answer the given question.

The remaining $21 \%$ (22) of respondents, 10 men and 12 women, stated that they liked it as well as they disliked it, or that they would like it under certain conditions. The types of answers were as follows: 
- It would be great in some areas, but it would be necessary to find a replacement job for people whose jobs were filled by robots.

- Depends on the job position.

- This is good if the robots perform difficult, dangerous or monotonous tasks.

- Yes, in the event that robots replace humans only where it is necessary and useful.

- Yes, as long as it does not endanger the jobs of employees and makes the working environment more pleasant.

- Yes, if the robots were not completely in every workplace.

- Certainly not as a complete replacement for human activity, but certainly as a complement to work.

The assumption that $48 \%$ of respondents would welcome the presence of robots in every workplace was not confirmed.

\section{Drones}

The question about drones was as follows:

Would you like if in the future the shipments that you order, for example from an e-shop, would be delivered to you via drones?

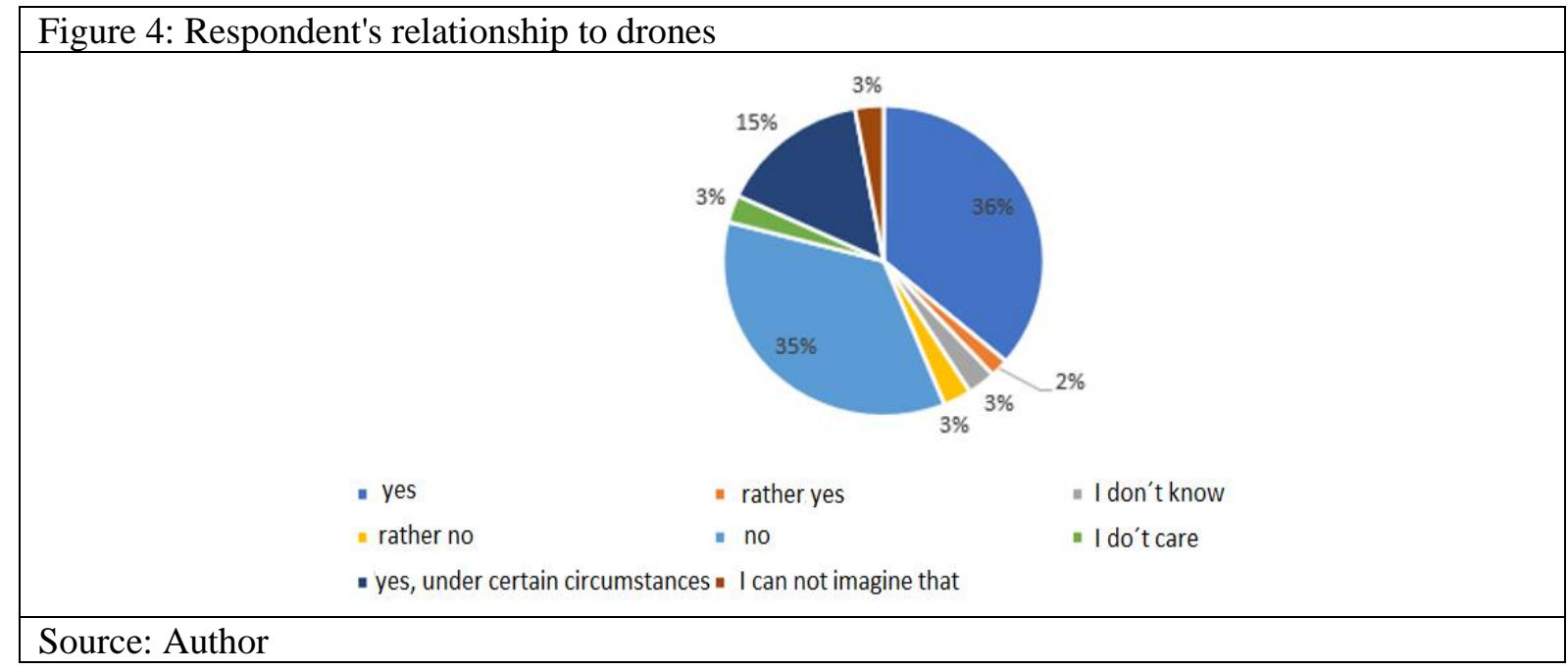

The answer that respondents would like it was given by $36 \%$ (38) of students, of whom 13 were men and 25 were women.

The answer that respondents would not like this was given by $35 \%$ (37) of students, of whom 8 were men and 29 were women. The reason was, for example, that according to students there is a high probability of losing the order, they do not consider it necessary, it is unimaginable for them or because it is better to be in contact with a person than with a machine when receiving an order.

Less than 3\% (3) of respondents, 1 man and 2 women, said they would rather not like it and less than $2 \%$ (2) of respondents, one woman and one man, said they would rather like it.

In total, less than $3 \%$ (3) of respondents, of whom all were women, did not know how to answer the given question.

An unbiased opinion, which means that the respondents did not care about it, was given by about $3 \%$ (3) of the respondents, of which 2 were men and one was a woman.

Less than 3\% (3) of respondents, 2 men and one woman, said they could not imagine it at present.

The remaining 15\% (16) of respondents, 5 men and 11 women, stated that they liked as well as they disliked it, or that they would like it under certain conditions. The types of answers were as follows:

- I have no problem with this if the delivery would be easier and faster than with other delivery methods.

- Yes, I would like it if it was possible to schedule a time when they will deliver the order.

- Yes, I would like it if such delivery is sufficiently secured.

- Yes, I would like it, but it would depend on the type of package. 
- I would not mind, but the implementation and realization of such a method of delivery would probably be difficult.

The assumption that more than $50 \%$ respondents would like the use of drones to deliver a shipment in the future was confirmed.

\section{Autonomous vehicles}

The question about autonomous vehicles was as follows:

Would you like autonomous vehicles (cars that would not need to be partially or completely serviced and would move on the road by themselves) to replace conventional cars in the future?

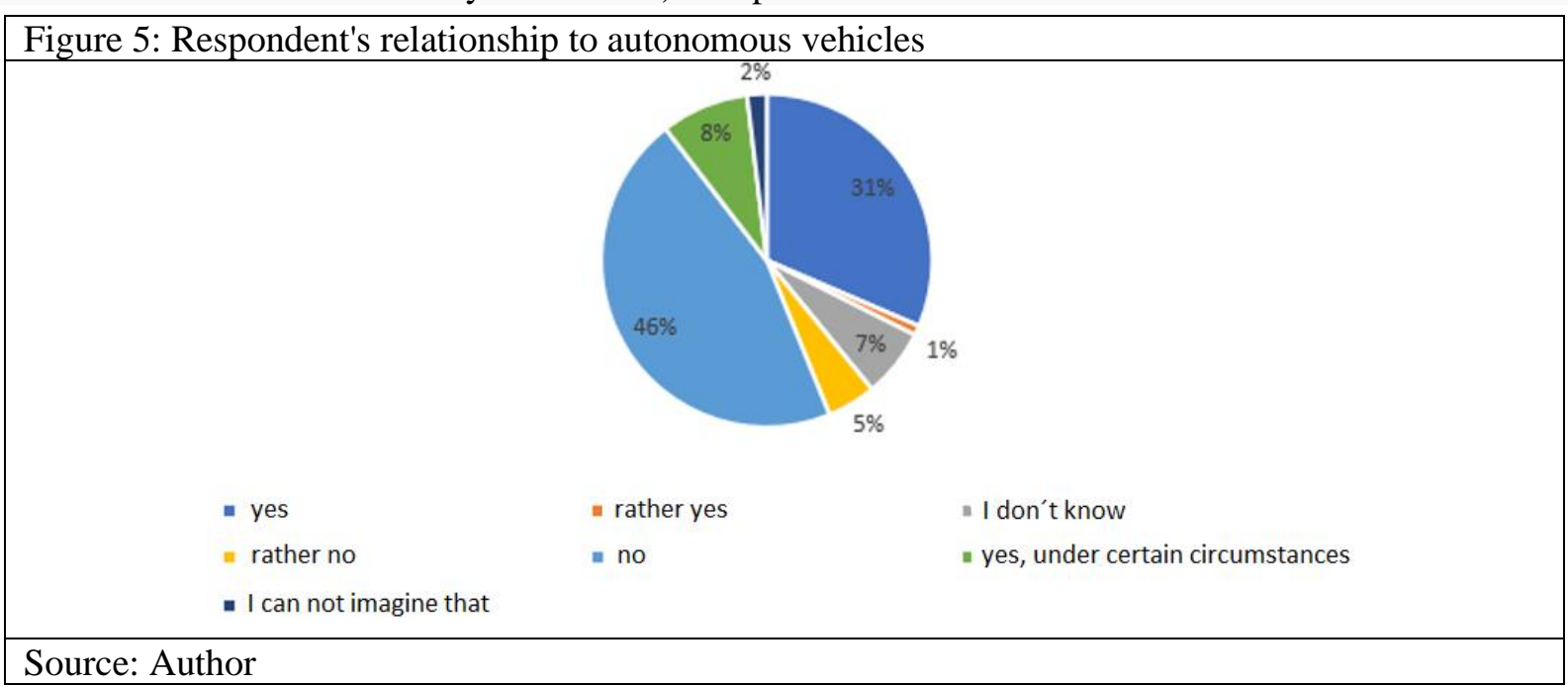

An answer that respondents would like it was given by $31 \%$ (33) of students, of whom 11 were men and 22 were women.

An answer that respondents would not like it was given by $46 \%$ (48) of students, of whom 13 were men and 35 were women. The reason was, for example, that the driving school would lose its meaning, respondents would not trust such technology, it would consider driving to be boring, or in case of failure, passengers would be in great danger.

Less than 5\% (5) of respondents, specifically 5 women, said they would rather not like it and less than $1 \%$ (1) of respondents, one woman, said she would rather like it.

Approximately 7\% (7) of respondents, of which 1 was a man and 6 were women, could not express their opinion on the given question.

Less than 2\% (2) of respondents, 2 men, said they could not imagine it at the present time.

The remaining $8 \%$ (9) of respondents, 5 men and 4 women, stated that they liked it as well as they disliked it, or that they would like it under certain conditions. The types of answers were as follows:

- Yes, I would like it if I was convinced that such technology could be relied on and that human lives would not be endangered.

- It would be appropriate in some situations (long routes), but the use of such technology could not cause the demise of classic cars.

- Yes, I would like it, because moving from one place to another would be easier.

- Yes, I would like it if such technology were not badly damaged and increased road safety.

- Yes, I would like it if the right conditions would be in place.

- Yes, I would like it if it reduced road accidents.

The assumption that $53 \%$ of respondents would like if autonomous vehicles replaced conventional cars in road traffic, was not confirmed.

\section{Conclusion}

Based on the results of the contribution of the survey, it is possible to see that the respondents, in this case specifically students of the selected educational institution, have a generally positive attitude towards technological innovation. None of the respondents stated that they had a negative attitude towards technological innovation. However, when it came to specific examples of such innovations, 
which were the use of robots / artificial intelligence, drones and autonomous vehicles, the respondents' opinions were different. Research assumptions were confirmed, in which it was stated that $50 \%$ of respondents are optimistic about the use of new technologies and more than 50\% of respondents would like the use of drones to deliver a shipment in the future. And the research assumptions, which stated that $48 \%$ of respondents would welcome the presence of robots in every workplace and $53 \%$ of respondents would like if autonomous vehicles replaced conventional cars in road traffic, were not confirmed.

Respondents had the biggest reservations, out of three selected technological innovations, against robots / artificial intelligence, where up to 57\% of respondents said they would certainly not like robots to replace people in their work at some point in the future. This is mainly because people are afraid that they could easily become unemployed and find it difficult to find work.

The survey also shows that respondents are largely interested in whether a particular technology would work without complications. They also often stated that specific technological innovations should be used only in cases and situations where it is necessary and in cases where such technology will significantly help people.

In general, this confirms the fact that, although people currently perceive both technological progress as well as technological innovation positively, they still keep some distance from them in some situations and cannot fully trust them.

\section{Acknowledgment}

KEGA project - Synergy of theory and practice in the study program "Distribution Technologies and Services"

\section{References}

Baum, JAC. (2001). Ecology: Organization. International Encyclopedia of the Social \& Behavioral Sciences. 4048 - 4053.

Gnap, J., Benova, D. (2018, June 29). Last Mile Logistics. Dvet Dopravy. Retrieved from http://www.svetdopravy.sk/logistika-poslednej-mile/

Jamnický, P. (2013, February 5). Technologické inovácie a ich vplyv na vznik nových trhov produktov. [Technological innovations and their impact on the emergence of new product markets] Retrieved from http://www.akademickyrepozitar.sk/sk/repozitar/technologicke-inovacie-a-ich-vplyv-na-vznik-novych-trhov-produktov.pdf

Janevic, M., Wikenbach, M. (2020, March). Characterizing urban last-mile distribution strategies in mature and emerging ecommerce markets. Transportation Research Part A: Policy and Practice. 133, 164 - 196.

Jankal, R., Jankalova, M. (2016). The application of The EFQM Excellence Model by the evaluation of Corporate Social Responsibility activities of companies. $3 d$ Global Conference on Business, Economics, Management nad Tourism (BEMTUR). 39, 660 - 667.

Lee, HL., Chen, Y., Gillai, B., Rammohan, S. (2016, June). Technological Disruption and Innovation in Last-Mile Delivery. White Paper. 1 - 26. Retrieved from https://www.gsb.stanford.edu/sites/default/files/publication-pdf/vcii-publicationtechnological-disruption-innovation-last-mile-delivery.pdf

Madlenak, R., Madlenakova, L. (2014) Digital advertising system in urban transport system of Žilina town. Transport and Telecommunication. 15(3). 215 - 226.

OECD. Defining innovation. Retrieved May 26, 2021, from

https://www.oecd.org/site/innovationstrategy/defininginnovation.htm

Pathan, AK. (2018, November 14). Technological advancements and innovations are often detrimental for concerned technology companies. International Journal of Computers and Applications. 40(4), 189 - 191.

Rosenberg, N. (1976). Perspectives on Technology. New York, NY: Cambridge University Press.

Scherer, FM. (2001). Innovation and Technological Change, Economics of. International Encyclopedia of the Social \& Behavioral Sciences. 7530 - 7536.

Statistical office of the Slovak republic. Veda, technika a inovácie [Science, technology and innovation]. Retrieved May 26, 2021, from

https://slovak.statistics.sk/wps/portal/ext/themes/multi/science/metadata/!ut/p/z0/04_Sj9CPykssy0xPLMnMz0vMAfIjo8ziw3 wCLJycDB0N3M1DDA08_fyCQ8MsAo1DfUz0C7IdFQH86blD/

Strenitzerova, M., Gana, J. (2018). Customer Satisfaction and Loyalty as a Part of Customer-Based Corporate Sustainability in the Sector of Mobile Communications Services. Sustainability. 10/(5), 1657.

Wang, XO., Yuen, KF., Wong, YD., Teo, CC. (2020, August 17). E-consumer adoption of innovative last-mile logistics services: A comparison of behavioural models. Total Quality Management and Business Excellence. 31(11-12), 1381 - 1407. 